Article

\title{
In-Situ Observation of Adhesion Behavior During Ultrasonic Al Ribbon Bonding
}

\author{
Yasuo Takahashi ${ }^{1, *}$, Kazumasa Takashima ${ }^{2}$, Kouta Misawa ${ }^{2}$ and Yusuke Takaoka ${ }^{2}$ \\ 1 Joining and Welding Research Institute, Osaka University, 11-1, Mihogaoka, Ibaraki, Osaka 567-0047, Japan \\ 2 Graduate School of Engineering, Osaka University, 2-1, Yamadaoka, Suita, Osaka 567-0047, Japan; \\ kaztaka@casi.osaka-u.ac.jp (K.T.); kmisawa@casi.osaka-u.ac.jp (K.M.); ytakaok@casi.osaka-u.ac.jp (Y.T.) \\ * Correspondence: takasy@jwri.osaka-u.ac.jp; Tel.: +81-6-6879-4195
}

Received: 9 April 2019; Accepted: 28 April 2019; Published: 3 May 2019

\begin{abstract}
In-situ observation was performed on a transparent silica substrate during ultrasonic $\mathrm{Al}$ ribbon bonding, using a high-speed video camera with differing frame rates, $10^{4} \mathrm{fps}$ and $10^{3} \mathrm{fps}$, to clarify the adhesion behavior. The bonding process was observed as follows. Initially, friction slip occurred, producing multiple island streaks in the direction parallel to the ultrasonic vibration. The island streaks were formed as a scratch, due to surface waviness of the Al ribbon. Momentarily, a belt-shaped bond zone was formed at the center, normally due to the ultrasonic vibration. The island streaks could be clearly observed at $10^{4} \mathrm{fps}$. However, the central belt zone was unclear and appeared translucent at $10^{4} \mathrm{fps}$; although it was clear when observed at $10^{3} \mathrm{fps}$. The island streaks were unclear at $10^{3} \mathrm{fps}$. The positional relation of the island streaks and the central belt zone was confirmed from in-situ observation results of a twist and peel test of $\mathrm{Al}$ ribbon bonded to silica substrate. The central belt zone was between the island streaks and the silica substrate.
\end{abstract}

Keywords: ultrasonic bonding; in-situ observation; adhesion; friction slip; bonding mechanism; aluminum ribbon; silica glass; high speed video camera; laser Doppler measurement

\section{Introduction}

Solid state ultrasonic bonding renders it possible to bond similar and dissimilar materials directly and within a short duration [1-6]. Al ribbon bonding is applied to power electronics packaging as well as to $\mathrm{Al}$ wire bonding [1,6-8]. Various studies of solid state ultrasonic microjoining have been reported [1,7-25]. The dominant mechanism consists of friction slip, plastic deformation, frictional heating and interfacial reaction (interdiffusion) [9-14,22]. These mechanism elements influence each other; additionally, their contributions are changed by the bonding conditions (bonding force, $F_{b}$, and ultrasonic power, $\left.P_{u}\right)$ [1,3,9-13,16-18]. Frictional heating can soften materials when microjoining; however, the softening effect cannot be attributed to frictional heating alone [13,21]. The increase in frictional force (shear force) in a direction parallel to the bonding interface contributes to the softening effect [1,21,23-25], as it is related to frictional slip and interfacial adhesion.

Numerous on-line measurements and in-situ observations of temperature [3,10,18,21], interfacial frictional force (power) $[9,21,23-27]$, frictional slip (relative motion) at the bonding interface $[3,9,23,24$, 28], ultrasonic vibration [21,28-30], deformation behavior [29,31], contact resistance [32], and electrical signals from ultrasonic generators [33] during ultrasonic bonding have been performed. The on-line measurements and in-situ observations are extremely useful and informative for comprehension of ultrasonic microjoining. Because the bonding interface is typically invisible, it is not simple to directly observe the bonding interface during the bonding process. Therefore, in general, off-line observations of the bonded interface have been implemented $[1,2,11,12,14,15,17,19,22,28]$; in lieu of this, numerical analyses of bonding processes have been performed $[4,13,18,34-39]$. A few studies 
of the direct observation have been reported for $\mathrm{Al}$ wire bonding [1,29] and $\mathrm{Al}$ ribbon bonding [1]; however, these are insufficient for understanding the ultrasonic bonding process.

If the bonding condition is appropriate, the general bonding process is as follows. Immediately after ultrasonic vibration is introduced in a direction parallel to the bonding interface, the friction slip occurs initially. The surface oxide film is scrubbed by the ultrasonic vibration and locally broken [16,22]. Then, the clean metallic surface is locally created, that is, local adhesion is produced. The local adhesion indicates that the friction coefficient at the bonding interface increases, that is, an increase in the shear force [13,21,23-26]. Shear stress is a component of equivalent stress which is the driving force behind plastic deformation [34-36,39]. The rate sensitive bonding materials are easily deformed by the enhanced equivalent stress, causing the softening effect. The uniaxial yield stress normal to the bonding interface apparently decreases [16,31]. In ball (or wedge wire) bonding, the side surface can be folded to the substrate due to the plastic deformation facilitated by the softening effect. The apparent bonded (or contact) area grows to the peripheral area. This is the fold mechanism which is redefined as the macro fold mechanism in the present paper. The sequence mechanism from friction slip to fold was defined as "slip and fold mechanism" in a previous paper [1]. Some microslips occur at the peripheral bond area after the macro fold is complete [11,12].

As the shape of the ribbon is roughly flat, compared with that of $\mathrm{Au}$ ball and $\mathrm{Al}$ wire, the ribbon bonding exhibits a different mode from ball (or wire) bonding. The macro fold mechanism works easily and the apparent contact width rapidly increases in Al ribbon bonding. Then, numerous strips (island streaks) are formed in a direction parallel to the ultrasonic vibration; additionally, a belt-shaped bond-area (belt zone) is formed at the central bonded area normal to the direction of ultrasonic vibration. However, the adhesion behavior cannot be clearly explained using only slip and the macro fold mechanism. Therefore, in the present study, the in-situ observation of the interfacial adhering process during the ultrasonic bonding between $\mathrm{Al}$ ribbon and transparent silica (crystal glass) substrate is performed using a high-speed video camera with frame rates of $10^{4} \mathrm{fps}$ or $10^{3} \mathrm{fps}$. The bonding interface can be observed directly, using a transparent silica substrate. The adhering process is discussed, comparing the results observed at $10^{4} \mathrm{fps}$ with those of $10^{3} \mathrm{fps}$. The purpose of the present study is to understand the interfacial adhesion behavior during ultrasonic $\mathrm{Al}$ ribbon bonding. Furthermore, the complex adhesion behavior is discussed through the theoretical idea of the common bonding mechanism, consisting of friction slip, plastic deformation, and interfacial material reaction.

\section{Experimental Procedures}

Annealed pure aluminum ribbon made by Tanaka Denshi Kogyo, Japan was used in the present study. The purity was 99.99 mass\%. The width and thickness were $1.0 \mathrm{~mm}$ and $0.20 \mathrm{~mm}$, respectively. The surface roughness of the Al ribbon was measured using a stylus profilometer made by Kosaka Laboratory Limited (Ltd.), Japan. Because the surface roughness of the silica substrate was significantly lower than that of Al ribbon surface, the surface roughness of the silica substrate was ignored when local contact behavior was examined.

Figure 1 is a schematic illustration of the ultrasonic bonding apparatus and measuring system. The bonding tests were performed at room temperature (about $298 \mathrm{~K}$ ). The ultrasonic frequency used was $60 \mathrm{kHz}$. The bonding force, $F_{b}$, was $7 \mathrm{~N}$ and the ultrasonic power, $P_{u}$, was $3 \mathrm{~W}$ or $4 \mathrm{~W}$. A flat bonding tool was used. The chuck width was $250 \mu \mathrm{m}$ and the maximum surface roughness of the flat chuck-face was about $0.5 \mu \mathrm{m}$. A very simple bonding sequence was adopted. Initially, the bonding force was applied to the ribbon. The ribbon was kept pressed on the substrate for $400 \mathrm{~ms}$ to damp the vibration generated by the impact of the bonding force. Then, the ultrasonic vibration was applied for $400 \mathrm{~ms}$, parallel to the longitudinal direction of the $\mathrm{Al}$ ribbon. Finally, the bonding force was unloaded at $400 \mathrm{~ms}$ after stopping the ultrasonic vibration. The vibration of the tool top was measured by a laser Doppler vibrometer produced by PI-Polytec Ltd., Japan. The sampling rate was $2.56 \mathrm{MHz}$. The bonding interface image was obtained from the back of the silica substrate, using the high-speed video camera made by Nac Image Technology Ltd., Japan. The frame rate, $F_{\text {rate, }}$ was set at $10^{3}$ or 
$10^{4} \mathrm{fps}$. The shutter speeds in $F_{\text {rate }}=10^{3}$ and $10^{4} \mathrm{fps}$ were $1 \mathrm{~ms}$ and $5 \mu \mathrm{s}$, respectively. The bonding interface was illuminated with a light emitting diode (LED) ring lamps. Illumination using a spot laser pointer with a wavelength of $650 \mathrm{~nm}$ was added to the LED lamps, allowing for the adhesion behavior to be observed clearly at a high speed of $10^{4} \mathrm{fps}$. The correlation coefficients, $r$, of pixel gray scale intensities, $z(i, j)$, were calculated for examination of the image-matching between video captures and still images, where $(i, j)$ was the pixel position of digital images [3,24].

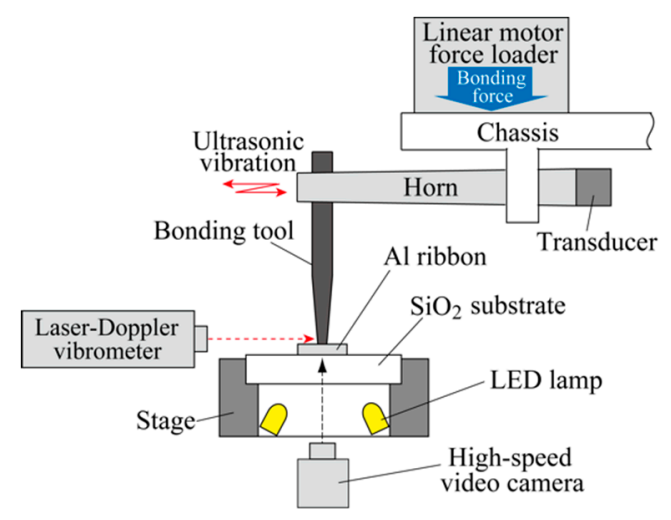

Figure 1. Schematic illustration of ultrasonic bonding apparatus and in-situ observation system.

If simple peel tests were carried out [14], the fracture occurred on the $\mathrm{Al}$ ribbon (or the plug fracture). In the present study, a twist and peel test was performed manually allowing the fracture to occur on the bonded interface. As illustrated in Figure 2, the end of the $\mathrm{Al}$ ribbon was twisted by $40^{\circ}$ in step 1 , applying a poor peeling tensile force. In step 2 , it was twisted by $20^{\circ}$ in the reverse direction and a poor tensile force was applied manually. As a next step, the tensile force was increased and the $\mathrm{Al}$ ribbon was peeled along the surface of the silica substrate in step 3 . The bonded interface during the twist and peel test was recorded through the high-speed video camera at $F_{\text {rate }}=10^{3} \mathrm{fps}$. The aim of the twist and peel test was to understand the origin of the interfacial fracture as well as to confirm the positional relation of the island streak and central belt zone in the direction normal to the bonding interface.

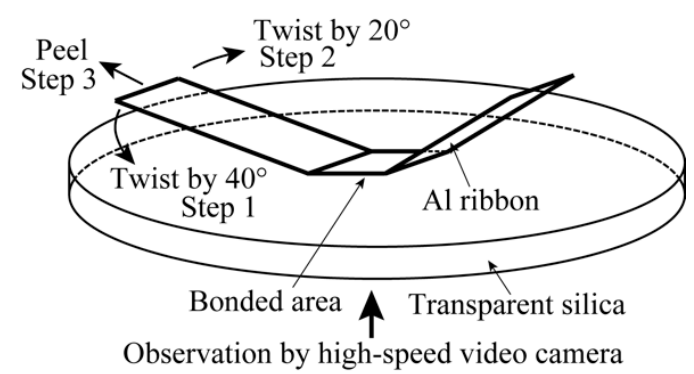

Figure 2. Schematic illustration of twist and peel test of $\mathrm{Al}$ ribbon bonded on silica substrate.

\section{Results}

\subsection{Behavior of Ultrasonic Vibration Amplitude}

Figure 3 shows the changes in the vibration amplitude of the tool head during the ultrasonic bonding. These were measured simultaneously with the in-situ observation of the bonding interface. The vibration amplitude exhibited different transient behavior in each ultrasonic bonding test. The amplitude became larger as the ultrasonic power was increased, under identical load conditions. Different transient behavior was derived from the curved and bent shape components of the Al ribbon. The amplitude always changed with time at the early stage of bonding; however, it decreased gradually 
and became constant with saturated values. The slip mode at the interface between the tool head and the upper surface of the $\mathrm{Al}$ ribbon could have caused the difference in the transient behavior.

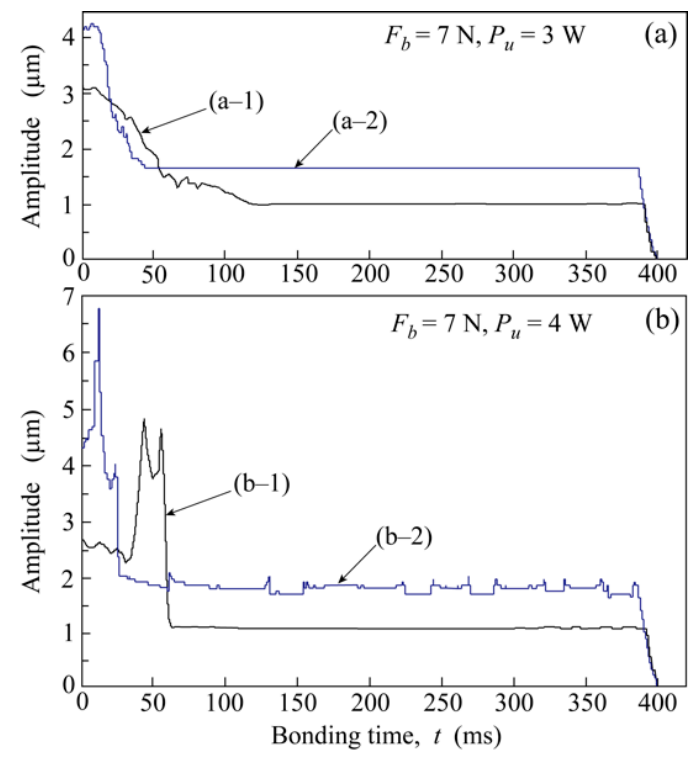

Figure 3. Change in ultrasonic vibration amplitude of tool head during ultrasonic bonding: (a) Under the bonding condition of $F_{b}=7 \mathrm{~N}$ and $P_{u}=3 \mathrm{~W}$. (a-1) Result measured simultaneously with the video taken at $F_{\text {rate }}=10^{4} \mathrm{fps}$. (a-2) Result measured simultaneously with the video taken at $F_{\text {rate }}=10^{3} \mathrm{fps}$; (b) Under the bonding condition of $F_{b}=7 \mathrm{~N}$ and $P_{u}=4 \mathrm{~W}$. (b-1) Result measured simultaneously with the video taken at $F_{\text {rate }}=10^{4} \mathrm{fps}$. $(\mathrm{b}-2)$ Result measured simultaneously with the video taken at $F_{\text {rate }}=$ $10^{3} \mathrm{fps}$.

\subsection{In-Situ Observation of Adhesion Behavior Obtained at a Frame Rate of $10^{4} \mathrm{fps}$}

Figure 4 shows the change in the video captures obtained at $F_{\text {rate }}=10^{4} \mathrm{fps}$ with the bonding time, $t$, under the bonding condition of $F_{b}=7 \mathrm{~N}$ and $P_{u}=3 \mathrm{~W}$. Long slip marks due to initial ribbon shaking are observed in Figure 4a. 10-20 ms was required for the macro folding to complete. The apparent bonded width achieved was twice the tool width; however, the overall (apparent) bonded area does not widen after $t=20 \mathrm{~ms}$. The striped pattern consisting of several island streaks was clearly observed at $t$ $=30-50 \mathrm{~ms}$, as shown in Figure $4 \mathrm{~b}$. The slip motion was observed even at the central area. The island streaks were dark gray and became longer with time. The number of islands increased; however, it did not appear to be copious. The appearance of the striped pattern did not change after $t=100 \mathrm{~ms}$. The slip motion was scarcely observed at $t>100 \mathrm{~ms}$. Both sides of the contact area appeared to repeat a touch and detach motion. No central belt zone was observed in the captures in Figure 4; however, something similar to a belt zone was vaguely observed in the video at $t>100 \mathrm{~ms}$ and it appeared translucent, approaching transparency.

Figure 5 shows the surface roughness along the width of the $\mathrm{Al}$ ribbon and the video capture at $t=100 \mathrm{~ms}$ in Figure 4. Figure 5a shows the surface roughness measured, without the cut-off [14]. Figure $5 b, c$ are the profiles after removing the wavelengths less than $10 \mu \mathrm{m}$ and $50 \mu \mathrm{m}$, respectively. Figure $5 \mathrm{c}$ expresses the surface waviness in the transverse direction of the $\mathrm{Al}$ ribbon. The wavelength was roughly $120 \mu \mathrm{m}$. The interval between the island streaks was about 60 to $140 \mu \mathrm{m}$ as shown in Figure $5 \mathrm{~d}$. The initial contact of $\mathrm{Al}$ ribbon on the silica surface was locally formed at the high peaks of the $\mathrm{Al}$ surface waviness. The island streaks were produced as a long footprint, at the interface between $\mathrm{Al}$ and silica. The peaks with a shorter wavelength, as shown in Figure $5 \mathrm{~b}$, had to be placed in contact with the silica sequentially in time. The footprints of the small peaks of surface roughness were not clearly captured by the high speed video camera. 

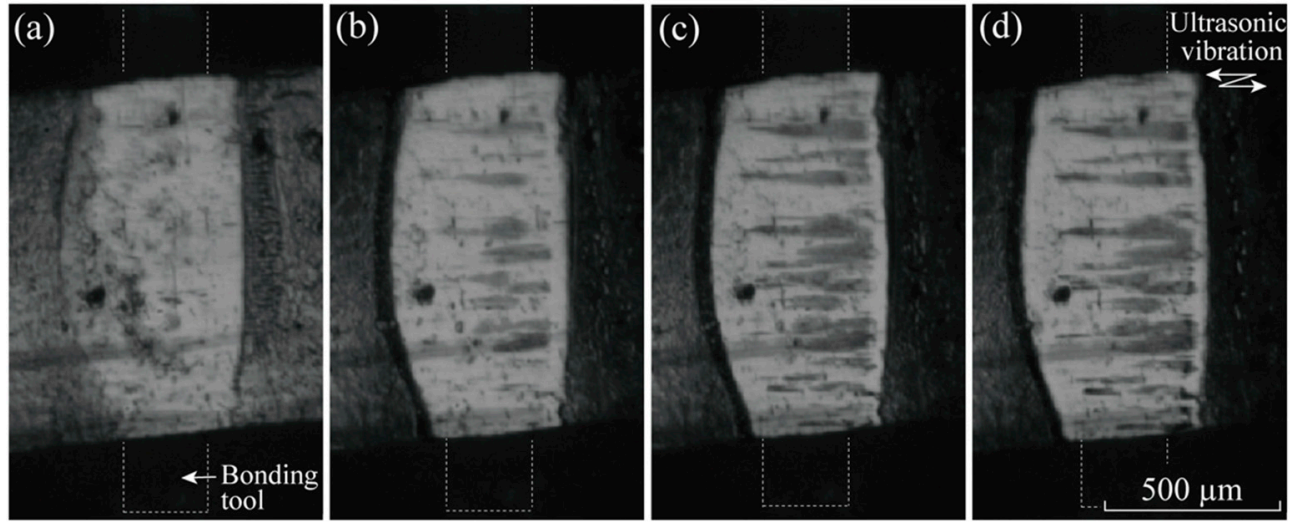

Figure 4. In-situ observation results (video captures) of the bonding interface between $\mathrm{Al}$ ribbon and silica substrate obtained at $F_{\text {rate }}=10^{4} \mathrm{fps}$. The bonding condition is $F_{b}=7 \mathrm{~N}$ and $P_{u}=3 \mathrm{~W}$. Simultaneous measurement result of ultrasonic vibration amplitude is shown in Figure 3 (a-1): (a) $t=3 \mathrm{~ms}$; (b) $t=$ $50 \mathrm{~ms} ;$ (c) $t=100 \mathrm{~ms}$; (d) $t=400 \mathrm{~ms}$.
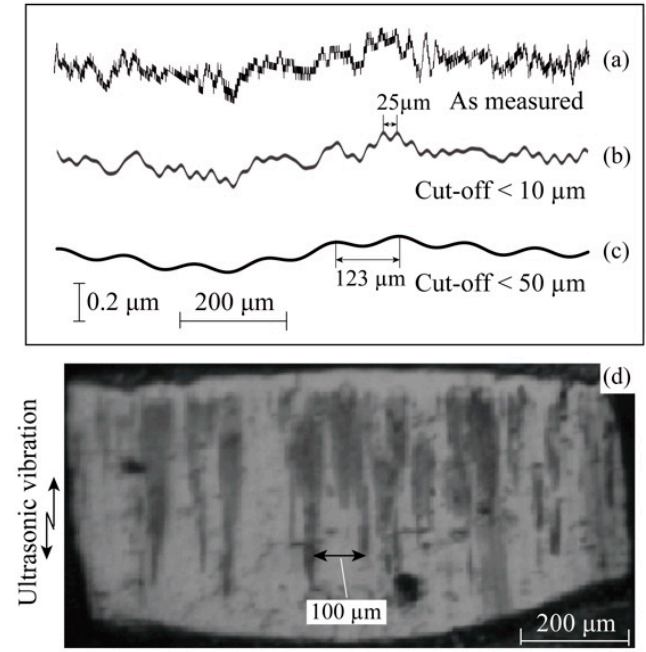

Figure 5. Comparison between surface roughness and video capture at $t=100 \mathrm{~ms}$. The surface roughness is that of the $\mathrm{Al}$ ribbon surface, measured in the width-direction of $\mathrm{Al}$ ribbon: (a) As measured surface roughness; (b) Surface profile after cutting off wavelength less than $10 \mu \mathrm{m}$; (c) After cutting off wavelength less than $50 \mu \mathrm{m}$; (d) Video capture at $t=100 \mathrm{~ms}$ under $F_{b}=7 \mathrm{~N}$ and $P_{u}=3 \mathrm{~W}$.

Figure 6 shows the comparison between the video image (a), immediately before bonding terminates, and two still images, (b) and (c), after bonding (cooling to the room temperature). The schematic drawings of each image are illustrated in the bottom portion of Figure 6 . The illumination differs between Figure 6 b,c. Areas A, B, and C are defined in the bottom portion of Figure 6 . In the still images, Area $B$ is divided into $B_{1}$ and $B_{2}$. A part of Area $C$ is detached from the substrate when unloading $F_{b}$. The central belt zone is scarcely visible in image (a). However, the central belt zone is clearly observed in still images (b) and (c) captured at a low shutter speed of $1 \mathrm{~ms}$. The correlation coefficients, $r$, are calculated between the digital images boxed by yellow dotted lines, as shown in Figure 6 . The $r$-values are 0.17 between (a) and (b), 0.12 between (a) and (c), and 0.67 between (b) and (c). The Al ribbon in image (a) leans slightly to the left; however, the image (a) is not treated with angularity correction. Central belt zones are not observed and all island streaks are not always visible in the image (a). Therefore, the $r$-values become very low between video captures and still images. It is also determined from the $r$-value between images (b) and (c) that the illumination influences the appearance of the bonded interface. 


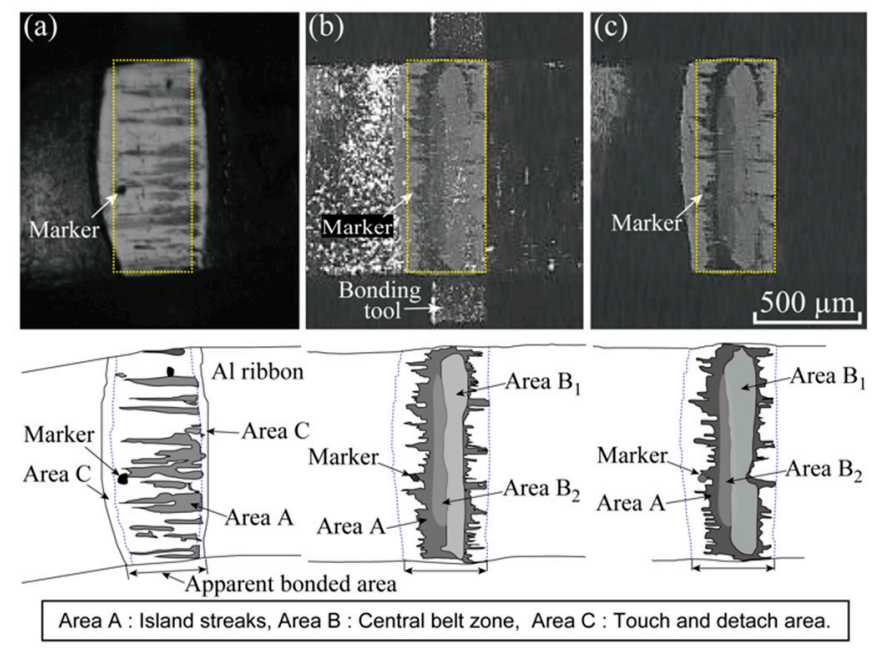

Figure 6. Comparison between video capture and two still images. The bonding condition is $F_{b}=7 \mathrm{~N}$ and $P_{u}=3 \mathrm{~W}$ : (a) Video capture at $t=400 \mathrm{~ms}$ taken at shutter speed of $5 \mu \mathrm{s}$; (b) Still image of bonded interface taken under bright illumination (light emitting diode (LED) ring lights + laser pointer); (c) Still image taken under dark illumination (only the LED lamps).

Figure 7 shows the video captured at $F_{\text {rate }}=10^{4} \mathrm{fps}$ under the bonding condition of $F_{b}=7 \mathrm{~N}$ and $P_{u}=4 \mathrm{~W}$. The macro fold appears to be complete by $t=8-10 \mathrm{~ms}$. The island streaks appeared clearly at $\mathrm{t}=35 \mathrm{~ms}$ after the macro fold terminated, as shown in Figure $6 \mathrm{~b}$, and increased as shown in Figure $7 \mathrm{c}$; the friction slip occurred after the macro fold was complete. The island streaks combined with one another. The central belt zone began to appear at approximately $t=50 \mathrm{~ms}$; however, it appeared to be translucent. The island streaks became longer and thickened gradually at $t=100 \mathrm{~ms}$ as seen in Figure $7 \mathrm{c}, \mathrm{d}$. The island streaks gradually became difficult to observe at the central area. The apparent bonded area widened slightly in the period from $t=10 \mathrm{~ms}$ to $100 \mathrm{~ms}$; however, it was noticeably constant after $t=100 \mathrm{~ms}$. The friction slip became extremely small at $t>100 \mathrm{~ms}$; however, a perfect stick was not achieved in all areas, that is, micro or nano slip was implied to continue, even in the later stage $(t>100 \mathrm{~ms})$. The belt zone must have been very thin, although the thickness was not measured.
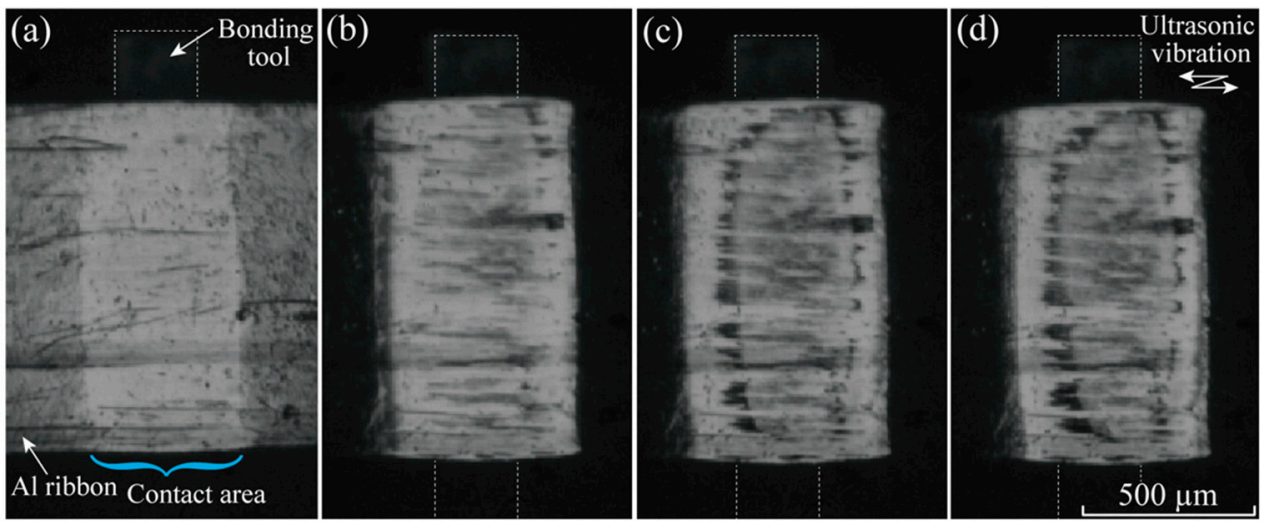

Figure 7. In-situ observation results (video captures) of the bonding interface between $\mathrm{Al}$ ribbon and silica substrate obtained at $F_{\text {rate }}=10^{4} \mathrm{fps}$. The bonding condition is $F_{b}=7 \mathrm{~N}$ and $P_{u}=4 \mathrm{~W}$. Simultaneous measurement result of ultrasonic vibration amplitude is shown in Figure 3 (b-1): (a) $t=3 \mathrm{~ms}$; (b) $t=$ $50 \mathrm{~ms}$; (c) $t=100 \mathrm{~ms}$; (d) $t=400 \mathrm{~ms}$.

Figure 8 shows the video capture of Figure $7 \mathrm{c}$ and its schematic drawing for confirming Areas A, $\mathrm{B}$, and $\mathrm{C}$. The peripheral bond area without island streaks is between Areas A and C. The peripheral microslip $[1,11,12]$ can occur in this area even after the macro fold finishes. 


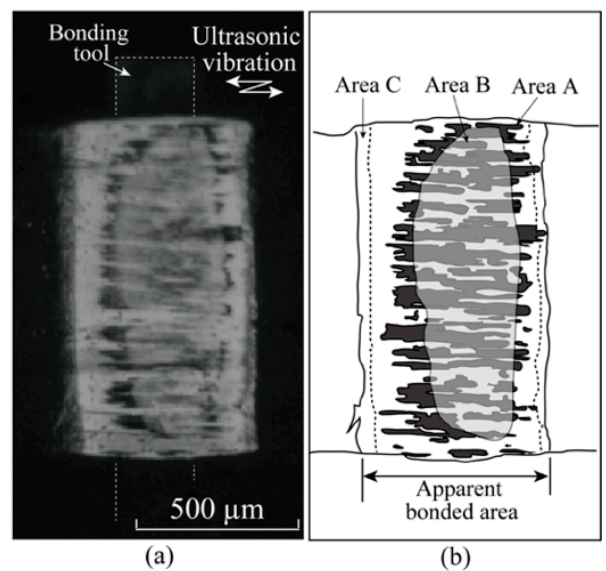

Figure 8. Explanation of Areas A, B, and $\mathrm{C}$ by illustrating the video capture at $t=400$ ms under $F_{b}=$ $7 \mathrm{~N}$ and $P_{u}=4 \mathrm{~W}$ : (a) Video capture at $t=100 \mathrm{~ms}$; (b) Schematic illustration of the video capture.

\subsection{In-Situ Observation of Adhesion Behavior Captured at a Frame Rate of $10^{3} \mathrm{fps}$}

Figure 9 shows the in-situ observation results captured at $F_{\text {rate }}=10^{3} \mathrm{fps}$ under bright illumination conditions. The bonding condition was $F_{b}=7 \mathrm{~N}$ and $P_{u}=3 \mathrm{~W}$. Under this shooting condition (at the shutter speed of $1 \mathrm{~ms}$ ), the $\mathrm{Al}$ ribbon was brightly captured, as shown in Figure $9 \mathrm{a}$, that is, reflected light was obtained from aluminum surface roughness. The apparent contact width became greater than that of the bonding tool at $t=1 \mathrm{~ms}$. Local adhesion occurred due to large sliding and is followed by the macro folding at bonding initialization. The island streaks appeared at $t=5-10 \mathrm{~ms}$; however, these were not clearly visible. Both of the uncontacted sides of the Al ribbon were warped (separated from the substrate). The central belt zone was observed at $t=50 \mathrm{~ms}$ and it became clear at $t=100 \mathrm{~ms}$. The central portions of the island streaks appeared to be covered gradually with the belt zone at $t>50 \mathrm{~ms}$.
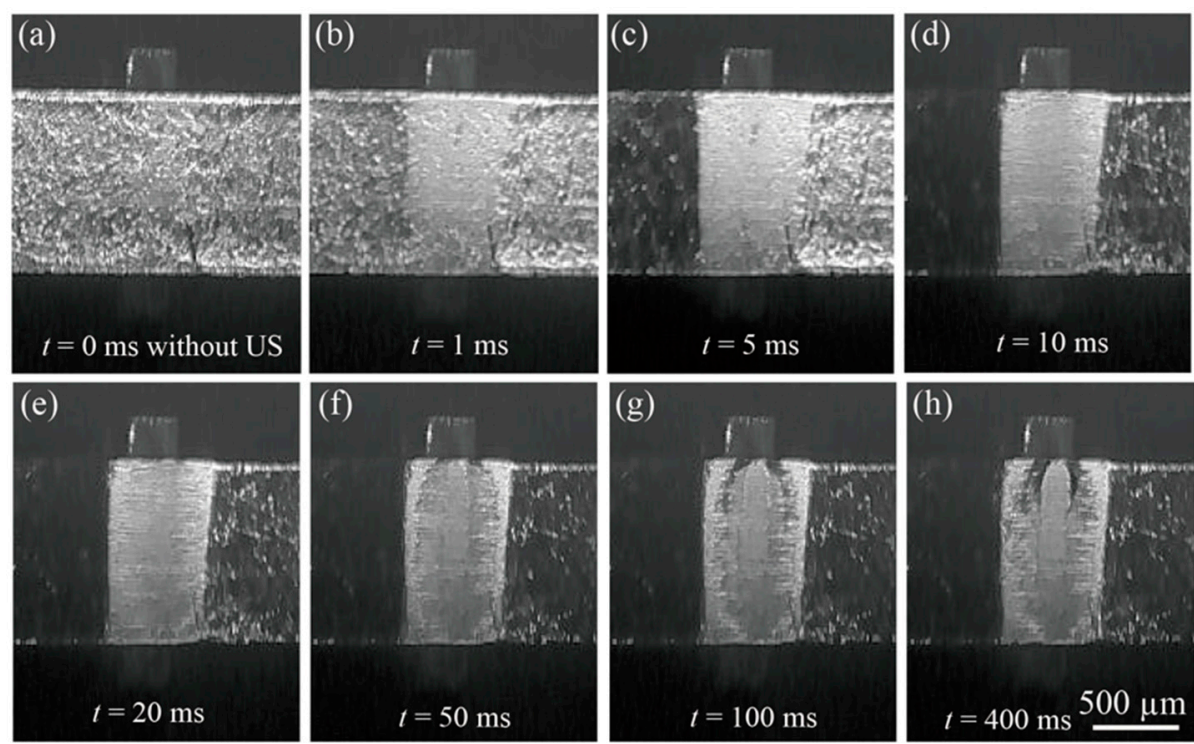

Figure 9. In-situ observation results (video captures) of the bonding interface between $\mathrm{Al}$ ribbon and silica substrate obtained at $F_{\text {rate }}=10^{3} \mathrm{fps}$. The bonding condition was $F_{b}=7 \mathrm{~N}$ and $P_{u}=3 \mathrm{~W}$. Simultaneous measurement result of ultrasonic vibration amplitude is shown in Figure 3 (a-2): (a) $t=$ 0 ms without ultrasonic vibration (US); (b) $t=1 \mathrm{~ms}$ immediately after introducing US; (c) Island streaks began to appear at $t=5 \mathrm{~ms}$; (d) $t=10 \mathrm{~ms}$; (e) $t=20 \mathrm{~ms}$; (f) Central belt zone began to be observed at $t=$ $50 \mathrm{~ms} ;(\mathrm{g}) t=100 \mathrm{~ms} ;$ (h) $t=400 \mathrm{~ms}$. 
Figure 10 shows the in-situ observation results captured under $F_{b}=7 \mathrm{~N}$ and $P_{u}=4 \mathrm{~W}$. The apparent bonded width achieved three times the tool width at $t=5 \mathrm{~ms}$, as shown in Figure 10c; however, the width decreased due to Al ribbon warping, as shown in Figure 10d. Several island streaks appeared at the central area at $t=5 \mathrm{~ms}$; however, the stripes became unclear at $t=20 \mathrm{~ms}$. The central belt zone was then observed, as shown in Figure 10f. Another belt zone appeared in the right-hand side of the central bond area, as shown in Figure 10g. A blackish gray area became visible around the central belt zone. This blackish area corresponded to be the peripheral part of the island streaks (Area A). Another gray area appeared outside of Area A, as shown in Figure 10f-h. This corresponded to be the peripheral bond area formed by the microslip mechanism $[1,11,12]$ after the macro fold was complete. The touch and detach area (Area C) could not be detected at $10^{3} \mathrm{fps}$. The peripheral bond area could contain the outermost touch and detach area.
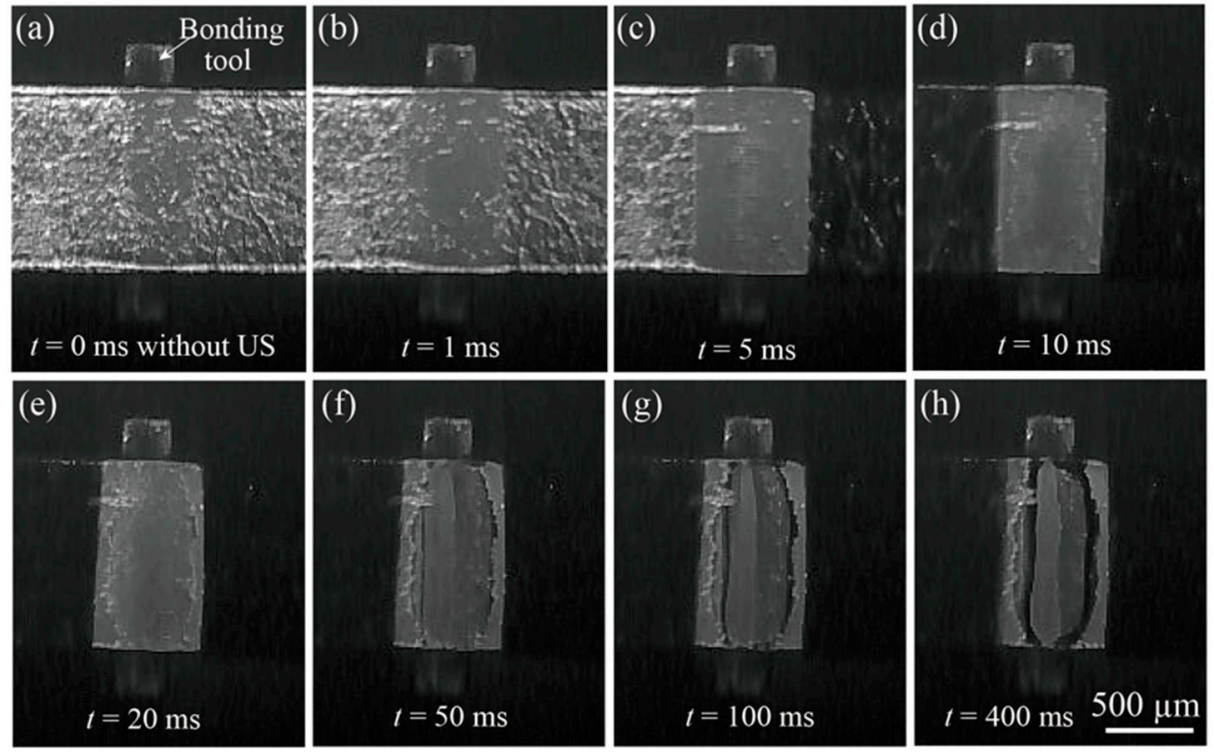

Figure 10. In-situ observation results (video captures) of the bonding interface between $\mathrm{Al}$ ribbon and silica substrate obtained at $F_{\text {rate }}=10^{3} \mathrm{fps}$. The bonding condition was $F_{b}=7 \mathrm{~N}$ and $P_{u}=4 \mathrm{~W}$. Simultaneous measurement result of ultrasonic vibration amplitude is shown in Figure 3 (b-2): (a) $t=$ 0 ms without ultrasonic vibration (US); (b) $t=1 \mathrm{~ms}$ immediately after introducing US; (c) Apparent bonded area increased at $t=5 \mathrm{~ms}$; (d) Apparent bonded area decreased at $t=10 \mathrm{~ms}$ due to Al ribbon warping; (e) $t=20 \mathrm{~ms}$; (f) Central belt zone began to be observed at $t=50 \mathrm{~ms}$; (g) $t=100 \mathrm{~ms}$; (h) $t=400 \mathrm{~ms}$.

\subsection{In-Situ Observation of the Fracture Process in Twist and Peel Test}

Figure 11 shows the video captures during the twist and peel test. The testing sequence is from (a) to (h) in Figure 11. It is important to observe the position and manner in which the fracture occurs, to confirm the positional relation of Areas $A, B$, and C. Area $A$ is divided into $A_{1}$ and $A_{2}$ for explaining the fracture behavior. Area $B$ is also classified into the three parts of $B_{1}, B_{2}$, and $B_{3}$. Once the rotating force was applied in a clockwise direction, the lower side of $B_{2}$ discolored to dark gray, as shown in Figure $11 \mathrm{~b}$. The upper side of $A_{1}$ and the lower side of $A_{2}$ were slightly blurry. $A$ few white fine stripes appeared in $\mathrm{C}$. Therefore, Areas A and $\mathrm{C}$ were not only in contact with the silica substrate but also experienced a chemical adhesion with the silica. The ribbon was observed rotating along the axis of a white area marked by the asterisk in Figure 11c. Area $B_{1}$ did not rotate at all and stood on the silica substrate, although partially peeled from the silica side. Conversely, $B_{2}$ and $B_{3}$ rotated. The central part of Area $A$ began to appear behind the original area of $\mathrm{B}_{2}$ and $\mathrm{B}_{3}$; it was observed clearly with twisting, as shown in Figure 11c,d. Figure 11d is the video captured upon twisting by $40^{\circ}$ in the clockwise direction (step 1 is complete). Figure 11e is the video capture at the beginning of step 2 . When the $\mathrm{Al}$ 
ribbon was twisted in a counterclockwise direction, a portion of Area A appeared clearly as blackish gray in the central area. The belt zone $\left(B_{1}, B_{2}\right.$, and $\left.B_{3}\right)$ existed in front of Area $A$. Both of $B_{2}$ and $B_{3}$ were behind $B_{1}$. The final fracture due to peeling (step 3 ) occurred in the neighborhood marked by the asterisk. As shown in Figure $11 \mathrm{~g}, \mathrm{~h}$, a portion of $\mathrm{B}_{1}$ almost remained on the silica substrate and appeared white, even after fracture. The peripheral edge of $B_{2}$ also remained on the silica side as a blackish gray marked as D, as observed in Figure 11g.
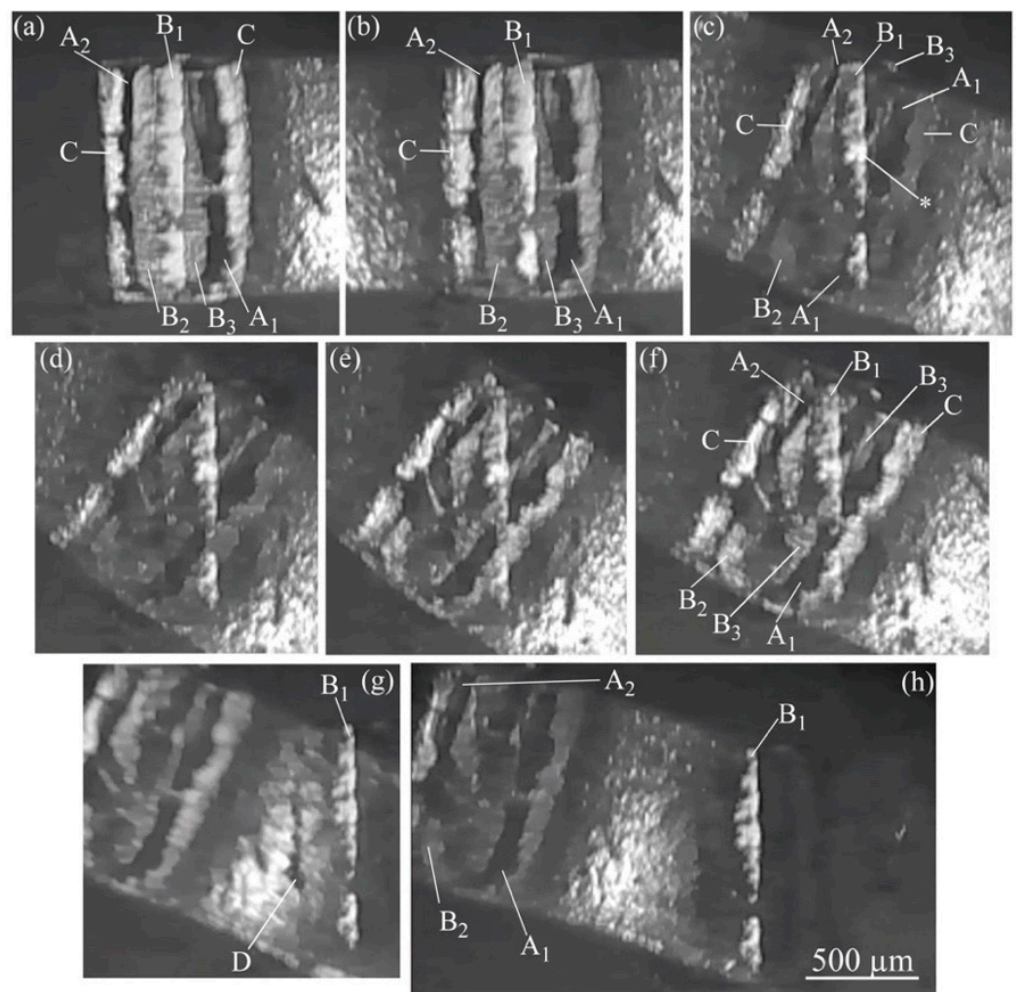

Figure 11. Twist and peel test of ultrasonic bonded interface between $\mathrm{Al}$ ribbon and silica substrate $\left(F_{b}=7 \mathrm{~N}\right.$ and $P_{u}=4 \mathrm{~W}$ ): (a) Before twisting; (b) Immediately after twisting Al ribbon (start time of stage 1); (c) When twisting $\mathrm{Al}$ ribbon by $25^{\circ}$ in clockwise direction; (d) Twisting by $40^{\circ}$ when step 1 is complete; (e) At the beginning of step 2 in counterclockwise direction; (f) Twisting by $\sim 18^{\circ}$ in step 2; (g) Immediately after fracture occurs due to peeling (step 3); (h) After fracture. Mark D and Area $B_{1}$ remain on silica side.

The fracture process was as follows. Initially, Area $C$ was broken, followed by Area A, and eventually Areas $B_{2}$ and $B_{3}$. Finally, Area $B_{1}$ was fractured. It was determined that the positional relation of each area in the direction normal to the bonded interface was Al ribbon/Area $\mathrm{A} /$ Areas $\mathrm{B}_{2}$ and $\mathrm{B}_{3} /$ Area $\mathrm{B}_{1} /$ silica substrate. The island streaks combined with one another; however, but Area A did not change to Area B. Area B was formed by the interfacial reaction between Area A and the silica substrate [14,22].

\section{Discussion}

Large shaking of $\mathrm{Al}$ ribbon usually occurs at the initialization of $\mathrm{Al}$ ribbon bonding. This often fluctuated, affected by the initial fixing situation. The bonding conditions of $F_{b}=7 \mathrm{~N}$ and $P_{u}=3$ or $4 \mathrm{~W}$ adopted in the present study provide some fluctuation to the initial large sliding; however, these can provide stable bonding in the early, middle, and later stages $[1,5,22-29,36]$. The friction slip was the dominant mechanism in the early stage. Plastic deformation became predominant in the middle stage; however, the friction slip occurred because the island streaks increased. The central belt zone grew; the interfacial reaction occurred in the later stage. 
Figure 12 illustrates the interfacial adhesion process in the ultrasonic bonding between the $\mathrm{Al}$ ribbon and transparent silica substrate. Immediately after large sliding, a few island streaks appeared as illustrated in Figure 12a. The number of island streaks increased and several islands combined with one another in Figure 12b. The central belt zone, B, was formed in the middle stage and widened to become $B_{1}$ in Figure 12c. Area $B_{2}$ was formed around $B_{1}$ in Figure 12c. Area $C$ was the touch and detach area. The peripheral bond area was between Area $A$ and Area $C$ even in the final stage. Areas $B_{1}$ and $B_{2}$ must consist of thin layers formed by some material reaction between Area $A$ and the silica substrate $[14,22,39-42]$.

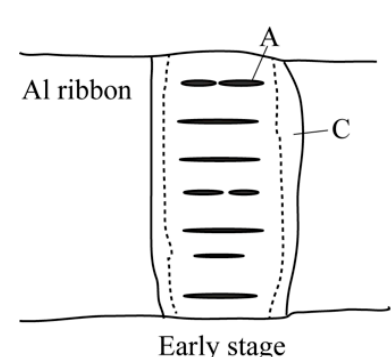

(a)

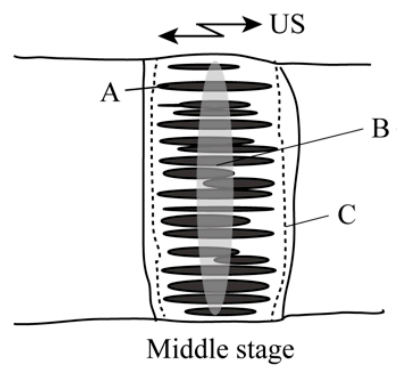

(b)

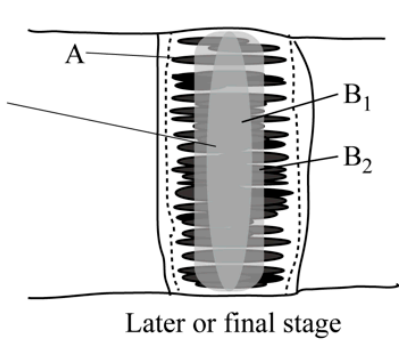

(c)

Figure 12. Schematic illustrations of interfacial bonding process between Al ribbon and silica substrate, which are observed from silica side; (a) Early stage after large sliding; (b) Middle stage in which island streaks increase and central belt zone B forms; (c) Later or final stage in which $B_{2}$ appears around $B_{1}$. $\mathrm{B}_{2}$ is behind $\mathrm{B}_{1}$.

Figure 13 illustrates the mechanisms of increasing adhesion area. Figure 13a expresses the cross section of the $\mathrm{Al}$ ribbon and silica substrate. The macro folding was primarily produced parallel to the direction of ultrasonic vibration. Even after the macro folding was complete, the apparent contact area had multiple small voids (or gaps) [16]. As illustrated in Figure 13b, blackish gray area were island streaks. Long voids existed between the island streaks. The voids were crushed by two mechanisms of microslipping (c) and microfolding (d) after the macro folding was complete. The voids between island streaks were required to shrink due to the microfold mechanism at the void tip. The island streaks combined with one another due to the microfold mechanism. This was the interfacial plastic deformation enhanced by ultrasonic power.

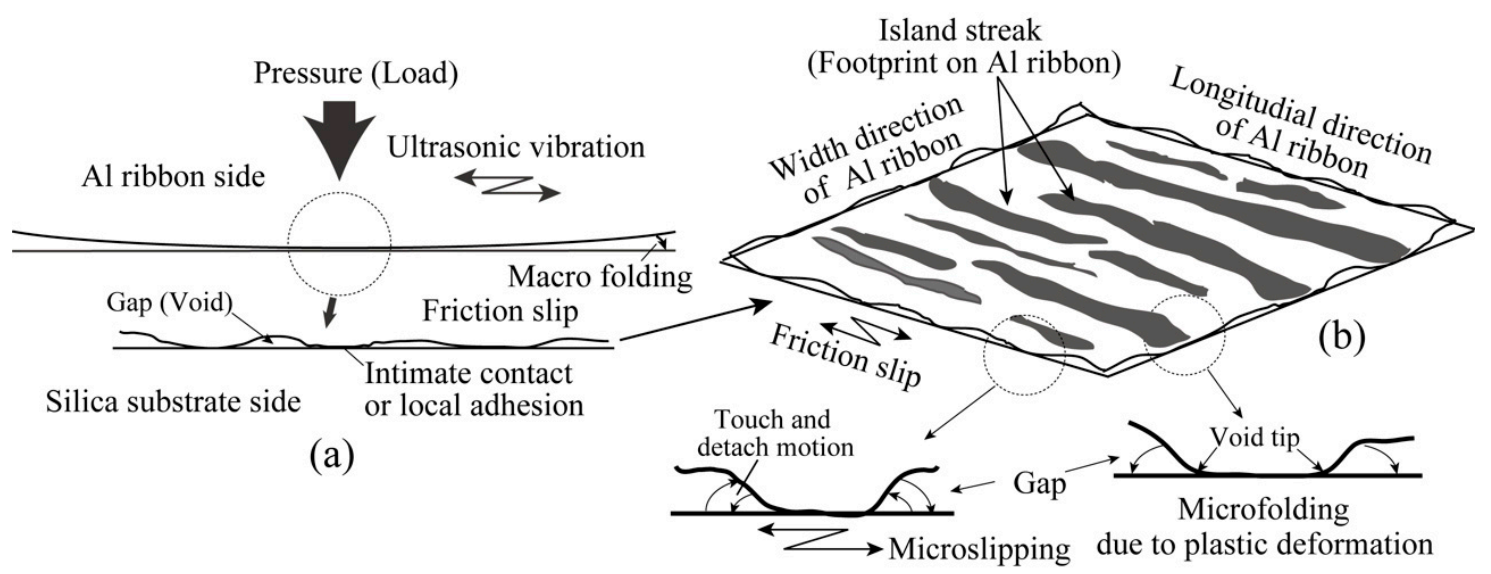

(c)

(d)

Figure 13. Schematic illustrations of bonded interface between $\mathrm{Al}$ ribbon and silica substrate; (a) Cross section parallel to US direction; (b) Drawing of bonded interface and island streaks; (c) Microslipping produced in longitudinal direction of $\mathrm{Al}$ ribbon; (d) Microfolding at void tip produced in width-direction of $\mathrm{Al}$ ribbon. 
A mechanical alloying could be produced at the bonding interface by ultrasonic vibration [42-44]. It is necessary to microscopically analyze the interfacial reaction layers at the bonded interface [42-45]. It is also important to develop monitoring systems for measuring the change in ultrasonic vibration and interfacial shear force for ensuring the bonding process $[3,21-28,46,47]$, because the bonding interface is not always directly observed. Furthermore, fundamental studies of adhesion would be necessary to understand the adhering processes [40-42,48,49]. Multiple problems remain which are yet to be solved for full comprehension of the adhesion behaviors $[1,16,50]$.

\section{Conclusions}

The interfacial adhesion behavior during ultrasonic bonding between an $\mathrm{Al}$ ribbon and transparent silica substrate has been discussed based on the in-situ observation results, using a high-speed video camera with the different frame rates of $10^{4} \mathrm{fps}$ and $10^{3} \mathrm{fps}$. The bonded area has been classified into four parts: the island streaks, the central belt zone, the peripheral bond area, and the outermost touch and detach area. The morphologies and the appearances of each bonded area appeared to be different and affected by the frame rate and illumination (luminous intensity); however, the essential qualities of each area were identified by analyzing the in-situ observation results. The primary results obtained are as follows:

(1) Immediately after introducing the ultrasonic vibration, the ribbon was largely shaken, that is, a large friction slide occurred. Initial poor adhesion was locally produced. Macro-folding arose and the apparent contact width increased.

(2) The island streaks were clearly observed at $10^{4} \mathrm{fps}$. Conversely, the central belt zone looked translucent at $10^{4} \mathrm{fps}$; although it was clear when observed at $10^{3} \mathrm{fps}$. The island streaks were unclear at $10^{3} \mathrm{fps}$.

(3) The island streaks were formed as a footprint derived from the $\mathrm{Al}$ surface waviness. The island streaks grew long and parallel to the direction of ultrasonic vibration.

(4) The central belt zone was formed, normal to the direction of ultrasonic vibration. The island streaks did not change into the central belt zone. The central belt zone was clearly captured at $10^{3} \mathrm{fps}$.

(5) The central belt zone remained on the silica side after fracture in the twist and peel test.

(6) The central belt zone was between the island streaks and the silica substrate. The central belt zone must be formed by the interfacial reaction.

(7) Microslipping and microfolding mechanisms can occur in the ultrasonic bonding.

Author Contributions: Conceptualization, Y.T. (Yasuo Takahashi); Validation, Y.T. (Yasuo Takahashi), K.T., K.M.; Investigation, Y.T. (Yasuo Takahashi), K.T., K.M., Y.T. (Yusuke Takaoka); Writing—original draft preparation, Y.T. (Yasuo Takahashi); Writing-review and editing, Y.T. (Yasuo Takahashi).

Funding: This research received no external funding.

Conflicts of Interest: The authors declare no conflict of interest. The funders had no role in the design of the study, in the collection, analyses, or interpretation of data, in the writing of the manuscript, or in the decision to publish the results.

\section{References}

1. Takahashi, Y.; Fukuda, H.; Yoneshima, Y.; Kitamura, H.; Maeda, M. Solid-state microjoining mechanisms of wire bonding and flip chip bonding. ASME J. Electron. Packag. 2017, 139, 041010-1-041010-13. [CrossRef]

2. Higashi, Y.; Iwamoto, C.; Kawamura, Y. Microstructure evolution and mechanical properties of extruded $\mathrm{Mg}_{96} \mathrm{Zn}_{2} \mathrm{Y}_{2}$ alloy joints with ultrasonic spot welding. Mater. Sci. Eng. A 2016, 651, 925-934. [CrossRef]

3. Sasaki, T.; Watanabe, T.; Hosokawa, Y.; Yanagisawa, A. Analysis for relative motion in ultrasonic welding of aluminium sheet. Sci. Technol. Weld. Join. 2013, 18, 19-24. [CrossRef]

4. Li, H.; Cao, B.; Liu, J.; Yang, J. Modeling of high-power ultrasonic welding of Cu/Al joint. Inter. J. Adv. Manufac. Technol. 2018, 97, 833-844. [CrossRef] 
5. Geißler, U.; Schneider-Ramelow, M.; Reichl, H. Hardening and softening in AlSi1 bond contacts during ultrasonic wire bonding. IEEE Trans. Compo. Packag. Technol. 2009, 32, 794-799. [CrossRef]

6. Ni, Z.L.; Ye, F.X. Ultrasonic spot welding of aluminum alloys: A review. J. Manufac. Processes 2018, 35, 580-594. [CrossRef]

7. Park, S.; Nagao, S.; Sugahara, T.; Suganuma, K. Mechanical stabilities of ultrasonic Al ribbon bonding on electroless nickel immersion gold finished Cu substrates. Jpn. J. Appl. Phys. 2014, 53, 04EP06-1-04EP06-6. [CrossRef]

8. Nwanoro, K.C.; Lu, H.; Yin, C.; Bailey, C. An analysis of the reliability and design optimization of aluminium ribbon bonds in power electronics modules using computer simulation method. Microelectron. Reliab. 2018, 87, 1-14. [CrossRef]

9. Schwizer, J.; Mayer, M.; Bolliger, D.; Paul, O.; Baltes, H. Thermosonic ball bonding: Friction model based on integrated microsensor measurements. In Proceedings of the 24th IEEE/CPMT Int'1 Electronics Manufacturing Technology Symposium, Austin, TX, USA, 18-20 October 1999; pp. 108-114. [CrossRef]

10. Mayer, M.; Paul, O.; Bolliger, D.; Baltes, H. Integrated temperature microsensors for characterization and optimization of thermosonic ball bonding process. IEEE Trans. Compo. Packag. Technol. 2000, 23, 393-398. [CrossRef]

11. Lum, I.; Jung, J.P.; Zhou, Y. Bonding mechanism in ultrasonic gold ball bonds on copper substrate. Mettal. Mater. Trans. A 2005, 36A, 1279-1286. [CrossRef]

12. Lum, I.; Mayer, M.; Zhou, Y. Footprint study of ultrasonic wedge-bonding with aluminum wire on copper substrate. J. Electron. Mater. 2006, 35, 433-442. [CrossRef]

13. Takahashi, Y.; Suzuki, S.; Ohyama, Y.; Maeda, M. Numerical analysis of interfacial deformation and temperature rise during ultrasonic Al ribbon bonding. J. Phys. Conf. Ser. 2012, 379, 012028-1-012028-11. [CrossRef]

14. Zhang, G.; Takahashi, Y.; Heng, Z.; Takashima, K.; Misawa, K. Ultrasonic weldability of Al ribbon to Cu sheet and the dissimilar joint formation mode. Mater. Trans. 2015, 56, 1842-1851. [CrossRef]

15. Dohle, R.; Petzold, M.; Klengel, R.; Schulze, H.; Rudolf, F. Room temperature wedge-wedge ultrasonic bonding using aluminum coated copper wire. Microelectron. Reliab. 2011, 51, 97-106. [CrossRef]

16. Long, Y.; Twiefel, J.; Wallaschek, J. A review on the mechanisms of ultrasonic wedge-wedge bonding. J. Mater. Process. Technol. 2017, 245, 241-258. [CrossRef]

17. Zhou, Y.; Li, X.; Noolu, N.J. A footprint study of bond initiation in gold wire crescent bonding. IEEE Trans. Compon. Packag. Technol. 2005, 28, 810-816. [CrossRef]

18. Mayer, M.; Zwart, A. Ultrasonic friction power in microelectronic wire bonding. Mater. Sci. Forum 2007, 539-543, 3920-3925. [CrossRef]

19. Lee, J.; Mayer, M.; Zhou, Y.; Moon, J.T.; Persic, J. Influence of gold pick up on the hardness of copper free air ball. Microelectron. Reliab. 2011, 51, 30-37. [CrossRef]

20. Sakamoto, S.; Yoneda, Y.; Yanagimoto, T.; Fujino, J.; Kikuchi, M. Development of direct Al/Cu lead terminal ultrasonic bonding technology for power semiconductor chips. J. Smart Process. Soc. Jpn. 2015, 4, 196-201. [CrossRef]

21. Ando, M.; Maeda, M.; Takahashi, Y. Evolution of interfacial shear force during ultrasonic Al ribbon bonding. Mater. Trans. 2013, 54, 911-915. [CrossRef]

22. Seppänen, H.; Kaskela, A.; Mustonen, K.; Oinonen, M.; Hæggström, E. Understanding ultrasound-induced aluminum oxide breakage during wire bonding. In Proceedings of the IEEE Ultrasonics Symposium, New York, NY, USA, 28-31 October 2007; pp. 1381-1384. [CrossRef]

23. Gaul, H.; Schneider-Ramelow, M.; Reichl, H. Analysis of the friction processes in ultrasonic wedge/wedge-bonding. Microsyst. Technol. 2009, 15, 771-775. [CrossRef]

24. Gaul, H.; Shah, A.; Mayer, M.; Zhou, Y.; Schneider-Ramelow, M.; Reichl, H. The ultrasonic wedge/wedge bonding process investigated using in situ real-time amplitudes from laser vibrometer and integrated force sensor. Microelectron. Eng. 2010, 87, 537-542. [CrossRef]

25. Shah, A.; Mayer, M.; Qin, I.; Huynh, C.; Zhou, Y.; Meyer, M. Ultrasonic friction power during thermosonic Au and Cu ball bonding. J. Phys. D Appl. Phys. 2010, 43, 325301-1-325301-8. [CrossRef]

26. Shah, H.; Gaul, M.; Schneider-Ramelow, M.; Reichl, H.; Mayer, M.; Zhou, Y. Ultrasonic friction power during Al wire wedge-wedge bonding. J. Appl. Phys. 2009, 106, 013503-1-013503-8. [CrossRef] 
27. Shah, A.; Rezvani, A.; Mayer, M.; Zhou, Y.; Persic, J.; Moon, J.T. Reduction of ultrasonic pad stress and aluminum splash in copper ball bonding. Microelectron. Reliab. 2011, 51, 67-74. [CrossRef]

28. Sasaki, T.; Komiyama, K.; Pramudita, J.A. Influence of tool edge angle on the bondability of alminum in ultrasonic bonding. Mater. Process. Tech. 2018, 252, 167-175. [CrossRef]

29. Maeda, M.; Yoneshima, Y.; Kitamura, H.; Yamane, K.; Takahashi, Y. Deformation behavior of thick aluminum wire during ultrasonic bonding. Mater. Trans. 2013, 54, 916-921. [CrossRef]

30. Zhong, Z.W.; Goh, K.S. Investigation of ultrasonic vibrations of wire-bonding capillaries. Microelectron. J. 2006, 37, 107-113. [CrossRef]

31. Shuto, T.; Asano, T. In situ observation of ultrasonic flip-chip bonding using high-speed camera. Jpn. J. Appl. Phys. 2015, 54, 030204-1-030204-5. [CrossRef]

32. Seppänen, H.; Kurppa, R.; Meriläinen, A.; Hæggström, E. Real time contact resistance measurement to determine when microwelds start to form during ultrasonic wire bonding. Microelectron. Eng. 2013, 104, 114-119. [CrossRef]

33. Feng, W.; Meng, Q.; Xie, Y.; Fan, H. Wire bonding quality monitoring via refining process of electrical signal from ultrasonic generator. Mech. Syst. Signal Proc. 2011, 25, 884-900. [CrossRef]

34. He, J.; Guo, Y.; Lin, Z. Theoretical and numerical analysis of the effect of constant velocity on thermosonic bond strength. Microelectron. Reliab. 2008, 48, 594-601. [CrossRef]

35. Takahashi, Y.; Shibamoto, S.; Inoue, K. Numerical analysis of the interfacial contact process in wire thermocompression bonding. IEEE Trans. Compon. Packag. Manuf. Technol. Part A 1996, 19, $213-223$. [CrossRef]

36. Takahashi, Y.; Inoue, M. Numerical study of wire bonding-Analysis of interfacial deformation between wire and pad. ASME J. Electron. Packag. 2002, 124, 27-36. [CrossRef]

37. Hu, C.M.; Guo, N.; Du, H.; Li, W.H.; Chen, M. A microslip model of the bonding process in ultrasonic wire bonders, part I: Transient response. Int. J. Adv. Manuf. Technol. 2006, 29, 860-866. [CrossRef]

38. Hu, C.M.; Guo, N.; Du, H.; Jian, X.M. A microslip model of the bonding process in ultrasonic wire bonders, part II: Steady state response. Int. J. Adv. Manuf. Technol. 2006, 29, 1134-1142. [CrossRef]

39. He, J.; Guo, Y.; Lin, Z. Numerical and experimental analysis of thermosonic bond strength considering interfacial contact phenomena. J. Phys. D Appl. Phys. 2008, 41, 165304. [CrossRef]

40. Takahashi, K.; Takahashi, Y.; Nishiguchi, K. A study about atomic interaction at the interfaces of transient-metal/ceramics. Trans. JWS 1993, 24, 70-73.

41. Hong, T.; Smith, J.R.; Srolovitz, D.J. Theory of metal-ceramic adhesion. Acta Metall. Matter. 1995, 43, $2721-2730$. [CrossRef]

42. Matsuoka, S.; Imai, H. Direct welding of different metals used ultrasonic vibration. J. Mater. Process. Tech. 2009, 206, 954-960. [CrossRef]

43. Maeda, M.; Sato, T.; Inoue, N.; Yagi, D.; Takahashi, Y. Anomalous microstructure formed at the interface between copper ribbon and tin-deposited copper plate by ultrasonic bonding. Microelectron. Reliab. 2011, 51, 130-136. [CrossRef]

44. Maeda, M.; Kitamori, S.; Takahashi, Y. Interfacial microstructure between thick aluminium wires and aluminium alloy pads formed by ultrasonic bonding. Sci. Technol. Weld. Join. 2013, 18, 103-107. [CrossRef]

45. Xu, H.; Liu, C.; Silberschmidt, V.V.; Pramana, S.S.; White, T.J.; Chen, Z.; Acoff, V.L. Behavior of aluminum oxide intermetallics and voids in $\mathrm{Cu}-\mathrm{Al}$ wire bonds. Acta Mater. 2011, 59, 5661-5673. [CrossRef]

46. Maeda, M.; Yamane, K.; Matsusaka, S.; Takahashi, Y. Relation between vibration of wedge-tool and adhesion of wire to substrate during ultrasoinc bonding. Q. J. JWS 2009, 27, 200s-203s. [CrossRef]

47. Suzuki, J.; Yamamoto, K.; Horita, M. The study of the load applied to the wire by ultrasonic vibration during wire bonding and bondability. In Proceedings of the 24th Symposium on Microjoining and Assembly Technology in Electronics, Yokohama, Japan, 30-31 January 2018; pp. 239-242. Available online: http://sps-mste.jp/mate2018/src/images/2018_2nd.pdf (accessed on 1 April 2019).

48. Takahashi, Y.; Matsusaka, S. Adhesional bonding of fine gold wires to metal substrates. J. Adhesion Sci. Technol. 2003, 17, 435-451. [CrossRef] 
49. Takahashi, Y.; Uesugi, K. Stress induced diffusion along adhesional contact interfaces. Acta Mater. 2003, 51, 2219-2234. [CrossRef]

50. Zhang, Z.W. Overview of wire bonding using copper wire or insulated wire. Microelectron. Reliab. 2011, 51, 4-12. [CrossRef]

(c) (C) 2019 by the authors. Licensee MDPI, Basel, Switzerland. This article is an open access article distributed under the terms and conditions of the Creative Commons Attribution (CC BY) license (http://creativecommons.org/licenses/by/4.0/). 